\title{
La delincuencia sexual: Un análisis jurídico y socio-criminológico*
}

\section{Sexual crime:}

\author{
A social-legal analysis criminological
}

\author{
Aura Elena Peña** \\ Meiby Estefanía Castillo****
}

Recibido: 23 de junio de 2012

Aprobado: 24 de agosto de 2012

\section{Resumen}

En el ámbito jurídico, social y criminológico el tema de la delincuencia es de perentorio abordaje en todas sus dimensiones y tipos, al constituir actos que no se corresponden con la legislación que regula a la sociedad. Concretamente, la delincuencia sexual desde el punto de vista socio-crimonológico constituye un problema inminente en la comunidad y que reclama estrategias para su atenuación, las cuales surgen del mismo proceso de la investigación. El objetivo de este estudio es analizar la delincuencia sexual desde una perspectiva jurídica y socio-criminológica, con base en su significado, psicopatía,

* Cómo citar este artículo: Peña, A., \& Castillo, M. (2013). La delincuencia sexual: un análisis jurídico y socio-criminológico. Revista CIFE, 15(22), pp. 49-63.

** Profesora del Postgrado en Ciencias Contables, Universidad de Los Andes, Mérida, Venezuela. Investigadora acreditada al PEI (ONCTI) Venezuela. Correo electrónico: auraelen59@hotmail.com.

*** Estudiante, Escuela de Criminología, Facultad de Ciencias Jurídicas y Políticas Universidad de Los Andes, Mérida, Venezuela. 
tipología, factores determinantes de las conductas sexuales de tipo desviada, sus consecuencias y la contribución de la criminología en su prevención. La metodología utilizada responde a un paradigma de naturaleza cualitativa, acudiendo a la hermenéutica como técnica de análisis e interpretación del contenido de textos, leyes y artículos científicos en materia de delincuencia. La principal conclusión es que el significado jurídico de la delincuencia sexual tiene un contenido diferenciador con respecto al socio-criminológico, por cuanto el primero se orienta hacia la determinación de lo punible, es decir, todo acto contra los bienes, costumbres y el buen orden de la familia, a los cuales se les asigna un castigo de naturaleza penal y, el segundo, se dirige hacia la determinación del delito asociado a la criminalidad sexual, como problema social y comunitario, el cual debe encontrar fórmulas de solución en las normas positivas.

Palabras clave: Delincuencia sexual; significado; psicopatía; criminología; factores; corolario.

Glasificación JEL: K0, K4

\section{Abstract}

On the legal, social and criminological the issue of crime is an imperative approach in all its dimensions and types to constitute acts that are not consistent with the laws governing society. Specifically, from the socio-crimonological viewpoint sexual crime is a problem inherent to the community and call for mitigation strategies, which arise from the same research process. The objective of this study is to analyze sexual crime from a criminological and socio-legal view based on its meaning, psychopathy, types, determinants of sexual behavior deviant type, its consequences and the contribution of criminology in its prevention. The methodology reflects a qualitative paradigm, attending technical hermeneutics as content analysis and interpretation of texts, laws and scientific articles on crime. The main conclusion is that the legal meaning of sexual crime have a different content with respect to socio-criminological, because the first is aimed to determine the offense, or any act against property, customs and the good order of the family, which are given a punishment of a criminal nature and, second, focuses on the determination of the crime associated with sexual crime, and social and community problem, which must find ways of solution positive norms.

Keywords: Sex offender; meaning; psychopathy; criminology; factors corollary.

Classification JEL: K0, K4 


\section{Introducción}

La mayoría de los estudiosos de la delincuencia, desde el sentido penal-normativo coinciden en su significado al considerarla como una serie de actos que son castigados según el marco normativo o jurídico que rige a una sociedad. En consecuencia, estos actos no concuerdan con aquellas conductas requeridas en una sociedad y se les asigna la denominación de delitos, dentro de los cuales se destacan los de tipo sexual. Al respecto, Fuenmayor (2009) afirma que los delitos sexuales son "aquellas conductas tipificadas en la ley penal que vulneran sustancialmente bienes jurídico-penalmente relevantes relacionados con la sexualidad, tales como la libertad, indemnidad, integridad o formación sexual" (p. 2).

Ahora bien, desde la arista socio-criminológica el delito es el objeto físico y psíquico y se presenta como "problema social y comunitario, caracterización que exige del investigador una determinada actitud para aproximarse al mismo. El delito es un problema de la comunidad, nace en la comunidad y en ella debe encontrar fórmulas de solución positivas" (Correa, 2006, p. 16). De esta manera, el delito es el objeto de la criminología desde la perspectiva del delincuente, y es la finalidad del derecho penal, desde el punto de vista de la aplicación de la norma. Ambas ciencias coinciden en que en la sociedad la delincuencia o conductas desviadas constituyen un problema social, el cual exige la aplicación de políticas de prevención al ser incluidas en los planes integrales de cualquier nación.

En lo atinente a la delincuencia sexual, la criminología concentra su atención en las conductas desviadas, es decir, en los actos de carácter criminal sobre los cuales se reclama determinar la responsabilidad penal para que mediante el Derecho Procesal Penal se imponga una sanción o pena y, a través del Derecho Penitenciario, se ejecuten y se implementen las correspondientes medidas de seguridad dirigidas a su prevención.

\section{Delincuencia sexual: su significado jurídico y socio-criminológico}

Desde la perspectiva jurídica, la delincuencia sexual corresponde con un hecho punible previsto en la ley en el marco de los delitos contra los bienes, costumbres y el buen orden de la familia, a los cuales se les asigna un castigo de naturaleza penal. En este sentido se sanciona como reo del delito a quien haya tenido la intención de realizar el hecho que lo constituye, exceptuando aquellos casos de "enfermedad mental suficiente para privarlo de la conciencia o de la libertad de sus actos" (Código Penal venezolano, art. 62). Desde el punto de vista criminológico, la delincuencia sexual es "una forma particular de criminalidad conocida en el ámbito penal criminológico como criminalidad sexual, por estar referida al sexo y dirigida hacia aquellas partes del cuerpo de las víctimas vinculadas con sus órganos genitales o sus partes erógenas, o con las partes que el criminal escoge para satisfacer su agresividad sexual”'(Martínez, 2001, p. 279) 
En el mismo orden de ideas se advierte que la criminalidad sexual, bajo el enfoque jurídico y socio-criminológico, se orienta desde la visión de las buenas costumbres, por cuanto "está vinculada por efectos de la estructuración legal europolatina, a los valores éticoreligiosos judeocristianos" (ibid, p. 280). De allí se califican como delictivos a determinados comportamientos en los cuales la motivación sexual se constituye en el fundamento determinante de la punibilidad.

Ahora bien, las buenas costumbres asociadas al uso correcto de las relaciones carnales, son aquellas a las que se refiere el Código Penal venezolano. Esto quiere decir, que la práctica viciosa o los hechos que están en contra de los postulados ético-jurídicos de la sociedad son opuestos a la concepción de uso correcto de las relaciones carnales.

En síntesis, la delincuencia o criminalidad sexual se conceptúa según Martínez (2001) como "la actividad criminal delictiva, sancionada penalmente, por agredir los postulados ético jurídicos que definen las relaciones carnales admitidas por la sociedad, legitimadas por las costumbres y reconocidas por la vida social como favorables para el desarrollo de una mejor existencia humana armoniosa"(p. 282).

Es importante dejar claro que los referidos postulados ético-jurídicos se relacionan, por una parte, con la honestidad y la concepción de libertad sexual bajo el criterio de la decisión de la persona en participar en el acto carnal y, por la otra, desde la perspectiva socio-criminológica, con las conductas desviadas que exigen del proceso de control penal, en aquellos casos de actos sexuales no compatibles con las normas de una sociedad.

\subsection{Psicopatía del delincuente sexual}

En esta sección se explica la psicopatía del delincuente sexual en términos de la afectación de su personalidad, es decir, de los patrones predictivos y conductuales referidos al victimario y no a las víctimas. Al respecto, González (s/f), considera que una de las variables del patrón del delincuente sexual se representa en la dirección en que se manifiesta el interés sexual, por cuanto la intensidad sexual varía de una persona con respecto a otra. "En el caso de los agresores sexuales esta intensidad puede ser muy elevada, lo que podría explicar su tendencia a la promiscuidad (incluso con niños), que sean incapaces de vincularse a una pareja, o que lleguen a la satisfacción fisica para satisfacer sus deseos sexuales" (p. 1).

En concordancia con las ideas anteriores, los delincuentes sexuales presentan características heterogéneas en cuanto a personalidad y psicopatología. El citado autor agrega, con respecto a los delincuentes sexuales que pueden o no tener trastorno de personalidad, y cuando lo hay, es principalmente de tipo limítrofe con dificultad en el control de impulsos y en lograr relaciones de intimidad. En el caso de violadores es más frecuente el trastorno de personalidad antisocial. En general, presentan distorsiones cognitivas, dificultades en el desarrollo de empatía y en la habilidad de entender y atribuir estados mentales a otros, lo que en la literatura se ha denominado la teoría de la mente (p. 3). 
Ahora bien, con base en las teorías de comportamiento humano, y por lo tanto, de la personalidad de Eysenck (1952, 1976, 1985, 1994), pueden evidenciarse los rasgos tales como la inteligencia, creatividad, y conducta criminal entre otros, bajo el concepto de "factores disposicionales que determinan la conducta regular y persistente en muchos tipos de situaciones diferentes" (Eysenck, En: Schmidt y otros, s/f, p. 9).

Las teorías dimensionales o factorialistas de Eysenck apuntan a la existencia de factores de la personalidad como dimensiones continuas sobre las cuales se pueden determinar las diferencias individuales. Las dimensiones básicas según estas teorías son: la extraversión $(\mathrm{E})$, el neuroticismo $(\mathrm{N})$ y el psicoticismo $(\mathrm{P})$. Estas tres dimensiones deben ser abordadas como categorías no excluyentes, es decir, "las personas pueden ser descritas en función del grado de $E, \mathcal{N} y$ P, y pueden ser ubicadas en algún punto del espacio tridimensional que estos suprafactores generan".

Ofreciendo una visión un tanto sintetizada de cada dimensión se tiene que: [1] un individuo será extravertido si es "sociable, vivaz, activo asertivo, buscador de sensaciones socializadas, despreocupado, dominante, espontáneo y aventurero" (Schmidt y otros, s/f, p. 10); [2] una persona neurótica muestra estados de ansiedad, depresión, tensión, timidez, tristeza, baja autoestima y sentimientos de culpa, entre otros y, [3] una persona con alto grado de psicoticismo es hostil, egocéntrica, impulsiva, antisocial, creativa, agresiva y poco empático, mientras que una persona con bajo grado de psicoticismo es responsable, social y convencional.

Por otra parte, siguiendo la tipología del delincuente sexual de Groth (1979), en Garrido (1989) aparecen tres componentes en los agresores sexuales: "hostilidad, poder y sexualidad. Las interrelaciones entre estos factores y la intensidad relativa con que son expresados, varía de un sujeto a otro" (p. 3).

En conclusión, hasta ahora no existe una teoría que describa la personalidad del delincuente sexual bajo estándares basados en características homogéneas, por cuanto cada individuo se enfrenta a factores que en muchos casos, son de naturaleza interviniente y a aquellos relativos a su propio interés sexual.

\section{Tipología de los delitos y conductas sexuales desde la acepción jurídica y criminológica}

\subsection{Delitos sexuales desde la acepción jurídica}

Desde la perspectiva jurídica, y específicamente, según el Código Penal venezolano, los delitos sexuales se ubican dentro de aquellos delitos contra las buenas costumbres, y el buen orden de las familias. En este sentido se incluyen la violación, el acto lascivo, el acto carnal, la seducción, el incesto, la prostitución o corrupción de menores, y los relativos a los ultrajes al pudor. 


\subsubsection{La violación}

La violación constituye un delito contra la libertad sexual como bien jurídico afectado, contemplado en el artículo 374 del Código Penal venezolano. Comprende el acceso carnal por vía vaginal, oral $\mathrm{u}$ anal realizado sin el consentimiento de la víctima, así como la introducción de objetos insidiosos o que simulen objetos sexuales.

\subsubsection{El acto lascivo}

El acto lascivo se refiere a la comisión de actos libidinosos sin relación sexual, sobre una persona de uno u otro sexo sin su consentimiento, es decir, valiéndose de los medios y aprovechándose de las condiciones o circunstancias relativas a vulnerabilidad de la víctima, edad, enfermedad mental, entre otras. Este delito está tipificado en el artículo 374 del Código Penal venezolano.

\subsubsection{El acto carnal}

El acto carnal, también denominado sinonimia (desde la perspectiva criminológica), consiste en "la penetración del órgano masculino en cavidad natural de la víctima, con el propósito de practicar el coito o un acto que lo reemplace, siendo indiferente que la penetración sea total o parcial, que se produzca o no desfloración; que llegue o no a la eyaculación y en consecuencia, que haya no goce genésico" (López Bolados, En: Chirinos, s/f, p. 9). Dicho de otra manera, en el acceso carnal no se exige que el acto se perfeccione desde el punto de vista fisiológico, ni que la víctima sea abusada o violentada, "pudiendo tratarse de una introducción incompleta. En la legislación penal no se discrimina si la actividad sexual es normal o desviada (parafilica), sólo se incrimina la falta de libertad consensual o la libre voluntad de la víctima" (Romi, 2010, p. 3).

\subsubsection{La seducción}

La seducción se configura en un delito en el cual interviene el engaño para materializar el acceso carnal por la vía vaginal, anal o bucal. Según el Código Penal venezolano en su artículo 378 se tipifica como todo acto carnal con persona mayor de 12 y menor de 16 , o ejecutarse en ella actos lascivos, sin ser su ascendiente, tutor ni institutor y aunque no medie ninguna de las circunstancias previstas en el artículo 374, tales como la violencia o amenazas, que constriña a alguna persona de uno u otro sexo. Igualmente, en el mismo artículo 378 ejusdem, la seducción es el acto carnal consentido con mujer mayor de 16 y menor de 21 años, bajo promesa matrimonial, y siempre que la mujer fuere conocidamente honesta.

\subsubsection{El incesto}

El incesto está representado en la práctica de sexo entre familiares cercanos, es decir, de relaciones sexuales entre individuos relacionados entre sí, bien se trate de parentesco por 
afinidad o por consanguinidad. Siguiendo lo establecido en el artículo 380 del Código Penal venezolano, se advierte que todo individuo que, en circunstancias capaces de causar escándalo público, tenga relaciones incestuosas con un ascendiente o descendiente, aunque fuere ilegítimo, con algún afín en línea recta o con un hermano o hermana, hermanos, consanguíneos o uterinos, será castigado con presidio.

\subsubsection{La prostitución o corrupción de menores}

La prostitución o corrupción de menores constituyen delitos por los cuales pudieran ser condenados aquellos que promovieren la práctica sexual lucrada o el uso de personas en material de tipo pornográfico, cuando dichas personas no han alcanzado la edad de consentimiento que requiere la ley. Al respecto, y de acuerdo con el artículo 381 del Código Penal venezolano, el que reiteradamente o con fines de lucro y para satisfacer las pasiones de otro, induzca, facilite o favorezca la prostitución o corrupción de alguna persona será castigado con prisión.

En materia de niños y adolescentes la Ley Orgánica para la Protección de Niños, Niñas y Adolescentes (2007), en los artículos 258, 259 y 260, establece en cuanto a explotación de niños, niñas y adolescentes, el castigo de prisión, por una parte, sobre aquel que fomente, dirija o se lucre de la actividad sexual; por la otra, sobre aquel que realice o participe en actos sexuales con un niño, niña o adolescente.

\subsubsection{Los ultrajes al pudor}

Los ultrajes al pudor son constituidos en "toda acción efectuada ante terceros que afecte la moral pública, por medio de exhibiciones corporales impúdicas, sexuales, genitales u obscenas, sin contacto con la víctima" (ibid., p. 6). Efectivamente, según el artículo 381 del Código Penal venezolano, los ultrajes al pudor se relacionan con toda afrenta a las buenas costumbres por actos cometidos en lugar público o expuesto a la vista del público y, el artículo 382, por su parte, establece también el ultraje al pudor por medio de escritos, dibujos u otros objetos obscenos, que bajo cualquier forma se hubieren hecho, distribuido o expuesto a la vista del público u ofrecido en venta.

\subsection{Conductas sexuales desviadas desde la acepción criminológica}

Desde el punto de vista criminológico, todos los tipos de delitos antes mencionados expresan una conducta de los victimarios que va en contra de la libertad sexual de sus víctimas. Son diversas las tipologías de los denominados agresores sexuales que materializan sus actos en delitos sexuales. En consecuencia, los agresores sexuales se pueden dividir siguiendo el criterio de la naturaleza del acto acometido en: pedófilos, agresores homosexuales, atacantes de mujeres adultas, necrofílicos, zoofílicos, entre otros. 


\subsubsection{La pedofilia}

La pedofilia consiste en un tipo de parafilia en la cual "hay una atracción sexual intensa, urgente, recurrente por los niños, existiendo casi exclusivamente apetito sexual y excitación incontrolables por los menores de 13 años. El pedofilico utiliza la seducción, violencia (incluyendo violación y riesgo de muerte), remunerar al menor para conseguir aceptación, induciendo incluso a la drogadicción y alcoholismo" (Devoto y Aravena, 2003, p. 1)

\subsubsection{La necrofilia}

La necrofilia consiste en la "inclinación por la muerte, perversión sexual de quien trata de obtener el placer erótico con cadáveres" (Gómez, 1995, p. 705). En otras palabras, la necrofilia es un tipo de parafilia en la cual el deseo sexual se encauza hacia los cadáveres, por tanto, es una desviación sexual de carácter extremo, que va desde la profanación de tumbas hasta el asesinato para posteriormente violar a las víctimas.

\subsubsection{La zoofilia}

La zoofilia también es otro tipo de parafilia consistente en la atracción sexual del humano hacia los animales. Dicho de otra forma, constituye un acto de crueldad y de abuso contra los animales. No obstante, el Código Penal venezolano no tipifica esta conducta como delito sexual.

\subsubsection{Otros tipos de parafilia}

Otros tipos de parafilia habituales en delincuentes sexuales son el fetichismo, el voyerismo y el exhibicionismo. El fetichismo, se relaciona con el alcanzar la excitación y el placer sexual mediante la agresión y sometimiento de la pareja, por ejemplo, utilizando el látigo. El voyerismo consiste en obtener placer sexual mediante la observación de los órganos sexuales y de la actividad sexual de otros. El exhibicionismo, por su parte, radica en la exposición de tipo deliberado y compulsivo de los genitales u otra parte del cuerpo en público, provocándose la satisfacción sexual mediante la masturbación, luego de la exhibición.

\section{Factores criminológicos determinantes de la delincuencia sexual}

Son diversos los factores que pudieran determinar la delincuencia sexual. Entre estos se destacan los de carácter psicológico y situacional.

[a] Factores psicológicos y situacionales: conducen a explicar "el desencadenamiento de las agresiones sexuales, estudiando la topografia de la excitación sexual, las actitudes hacia las mujeres y los niños, las distorsiones cognitivas y la competencia social de los agresores” (Posada y Salazar, 2005, p. 
38). En este apartado se pueden incluir los trastornos de la personalidad, la desadaptación, la baja autoestima, y la frustración.

Correa (2006), agrega otros factores de similar importancia:

[b] Factores socio-económicos: se incluyen en este ítem los fenómenos como el desempleo, la pobreza, la desigualdad social, y los ciclos económicos, influyen en dirección al incentivo o desincentivo de la acción criminal.

[c] Factores demográficos y socioculturales: se identifican en este grupo las variables que operan como incentivos, el grado de urbanización y la cantidad de hombres jóvenes y, aquellas variables que obran como barreras de ingreso a la actividad criminal; tales como la familia, la escuela y la misma comunidad. En la familia, la violencia se configura como el factor importante de riesgo de delincuencia futura en los tipos de violación, maltrato físico o psicológico y el abuso sexual.

[d] Factores relativos al entorno urbano y fisico: dentro de estos componentes prevalecen la urbanización incontrolada, la carencia de servicios y la promiscuidad, los medios de comunicación, entre otros.

Por otra parte, Lomelí y García (2000), consideran que los factores de riesgo que se han identificado y que contribuyen con la aparición o predisposición de las conductas sexuales son:

[1] Antecedentes de maltrato o abuso.

[2] La tríada de antecedentes de maltrato, frustración reiterada, y el estrés.

[3] Padres con baja autoestima, con un pobre control de impulsos, poca tolerancia a la frustración, y alcoholismo.

[4] Trastornos graves de personalidad.

[5] Pobreza, deprivación y estigmación cultural, la discordia conyugal secundaria a estrés social.

[6] Familia desintegrada con aislamiento social, convivencia múltiple (tíos, primos, abuelos) y conflictos entre padres.

[7] El machismo como factor sociocultural con las características extremas de agresividad, intolerancia, arrogancia y comportamiento sexual ofensivo hacia las mujeres.

[8] Becker subclasifica los factores en:

[a] Individuales: aislamiento social, conducta compulsiva, capacidades cognoscitivas limitadas y antecedentes de abuso sexual o físico; 
[b] Familiares: padres que ejercen una conducta coercitiva, familia que cree en la educación estricta, padres con pocas habilidades interpersonales y falta de empatía.

[9] Experiencias de violencia física o testigos de violencia física, cuidados discontinuos y rechazo en la familia.

[10] Falta de sentimientos entre el padrastro y la hijastra sobre todo cuando se conoce a ella en edad mayor a los doce años (p. 221).

No obstante, tal como lo advierten Martínez y otros (2008), "los factores adversos tienden a presentarse en conjunto y a actuar recíprocamente, hasta el punto de crear una situación que puede inducir a un individuo a cometer conductas ilícitas" (p. 302).

\section{Algunos corolarios de tipo jurídico, socio-criminológicos de la delincuencia sexual}

Partiendo de la óptica jurídica, los efectos de un delito sexual derivan, al igual que en los demás tipos de delitos, del bien "jurídicamente tutelado", de allí las conductas ilícitas contra ese bien o "débil jurídico" sean punibles por poner en peligro el bien que se ha establecido garantizar.

Desde el punto de vista jurídico, el corolario fundamental de un delito sexual se centra, por una parte, en la víctima desde el asunto de las garantías de protección hacia la misma y, desde la postura del victimario, los posibles efectos de naturaleza penal, representados en juicios largos, en testificaciones reiteradas, y por lo tanto, en la ejecución de las penas.

Siguiendo el enfoque socio-criminológico y desde la perspectiva victimológica, la principal consecuencia de la delincuencia sexual radica en que el delito "quiebra, fractura la vida de una persona. Se produce un cambio existencial en la vida de la víctima relacionada a sus costumbres, a sus hábitos, a su mirada hacia las demás personas, afecta sus relaciones, su confianza, su seguridad familiar, social y cultural" (Marchiori, s/f, p. 8).

Con el propósito de ampliar el abanico de consecuencias, desde la perspectiva de la víctima, agrega, Marchiori (s/f) que, "Las principales consecuencias en la víctima están lejos de ser comprendidas en su verdadera dimensión, especialmente las consecuencias emocionales y sociales. Freedman se refiere a un cambio total en el rol de las personas que está provocado por el delito y las consecuencias traumatizantes que provoca el delito. Una de las consecuencias más graves que produce el delito, especialmente en niños, víctimas de abuso sexual es el silencio de las víctimas y las dificultades en el relato de los procesos de victimización [...] vinculado a las amenazas del delincuente, a la relación familiar autor-víctima y a las características del delito, así como a las circunstancias particulares y familiaresculturales de la víctima y su familia" (pp. 8-9). 
Con el mismo enfoque anterior, Martínez (2001) considera que "las víctimas de los delitos sexuales son los sujetos que reciben de manera directa la acción delincuente, son en consecuencia, los receptores humanos del delito, los agredidos por el comportamiento criminoso" (p. 5). En síntesis, los delitos sexuales recaen sobre la víctima en lo que a su libertad, valores, pudor e inexperiencia sexual se refiere.

No obstante, las secuelas o efectos en las víctimas no son siempre las mismas. Tal como lo expresan Echeburúa y De Corral (2006):

"No todas las personas reaccionan de la misma manera frente a la experiencia de la victimización, ni todas las experiencias comparten las mismas características. El impacto emocional de una agresión sexual está modulada por cuatro variables: el perfil individual de la víctima (estabilidad psicológica, edad, sexo y contexto familiar); las características del acto abusivo (frecuencia, severidad, existencia de violencia o de amenazas, cronicidad, etc.); la relación existente con el abusador; y, por último, las consecuencias asociadas al descubrimiento del abuso"'" (p. 5).

\section{Contribución de la criminología en la prevención de la delincuencia sexual como problema social}

Primeramente, es prioritario comprender el alcance del término prevención para abordar cómo pudiera contribuir la criminología en este proceso. En efecto, la prevención "consiste en preparar o disponer lo necesario anticipadamente, para evitar un riesgo o la materialización de un determinado evento en el futuro; la prevención sería la suma de políticas tendientes a impedir el surgimiento o avance de la criminalidad" (Ávila, 2005, p. 6).

En relación con el aporte de la criminología en la prevención de la delincuencia sexual, resulta de gran importancia, primeramente, resaltar el trabajo que esta ciencia debe desarrollar en los asuntos teóricos y procesales de la delincuencia en general para, posteriormente, particularizar en materia de delitos sexuales. En este sentido, "en el marco de la teoría del continuo subcultural de la delincuencia, se ha sostenido que es posible distinguir nítidamente nichos etiológicos de conflictos diferenciales para los diversos tipos de delincuencia generales y específicos" (Martínez y otros, 2008, p. 303).

En este orden de ideas, la criminología contribuye en la prevención de los delitos, con independencia de su tipo, ofreciendo una explicación a cada caso en particular "considerando al ser humano como un ser biológico, social e individual y estudiando los factores que llevaron al sujeto a cometer una conducta antisocial" (Hikal, 2010, p. 3).

Ahora bien, tal como lo afirma Ávila (2005), en cuanto a las metodologías de contribución de la criminología en la prevención del delito. La selección de las metodologías y de los problemas a resolver en la práctica de las políticas criminales dependerá de las 
posiciones teóricas de sus actores (como en todas las áreas del saber). Podemos decir que existen dos grandes posiciones: una administrativa, situacional o pragmática, y la otra constituida por un modelo más amplio que viene de la criminología crítica. El primer modelo da prioridad a la parte sobre el todo, su vicio es la especificidad; el segundo da prioridad al todo sobre la parte, su vicio es la generalidad. En el segundo modelo (el de la criminología crítica) no se presenta de modo claro, una línea divisoria entre la política criminal y la política general (social, económica, urbanística, etc.) [...] Una política criminal alternativa debe ser una política de grandes reformas sociales para el desarrollo de la igualdad, de la democracia, de formas de vida comunitaria y civil alternativas y más humanas (pp. 8-9).

Unido al pensamiento anterior, es importante aclarar que los modelos de prevención del delito regularmente deben ser reformulados en procura de disminuir su frecuencia y/o de limitar su aparición. En este sentido, como lo ratifica De la Puente y Torres (2000), "la prevención del delito representa un constructo político e ideológico del cual se derivan múltiples acciones de orden práctico" (p. 8).

En lo relativo a la prevención de los delitos sexuales, la criminología debe orientar esfuerzos a estrategias de acción fundamentadas en "el refuerzo de estructuras familiares de los hogares donde residen niños y adolescentes de manera que sean capaces de orientar y supervigilar la conducta de los hijos, evitar episodios de violencia intrafamiliar y de maltrato al menor y las rupturas matrimoniales, de manera que los hijos no deban ser internados o sometidos a regímenes de custodia" (ibid, p. 10).

En el mismo sentido, Martínez (2001) afirma que "la cuestión de los delitos sexuales contra los niños y los adolescentes, requiere de una política criminal eficiente para que el sistema positivo de protección integral del niño y del adolescente no se convierta en una solución jurídica simbólica” (p. 3).

\section{Conclusiones}

De la revisión y análisis de la delincuencia sexual como fenómeno latente en la sociedad, desde la visión jurídica y socio-criminológica, se enuncian las siguientes aproximaciones como conclusiones esenciales:

1. El significado jurídico de la delincuencia sexual tiene un contenido diferenciador con respecto al criminológico por cuanto el primero se orienta hacia la determinación de lo punible, es decir, todo acto contra los bienes, costumbres y el buen orden de la familia, a los cuales se les asigna un castigo de naturaleza penal. El segundo se orienta hacia la determinación del delito asociado a la criminalidad sexual, como problema social y comunitario, el cual debe encontrar fórmulas de solución en las normas positivas. 
2. En cuanto a la psicopatía del delincuente sexual, han sido reconocidos los esfuerzos de investigadores para dar explicación, mediante sus teorías, a derivar un perfil de este tipo de sujeto activo delincuencial. No obstante, hasta ahora, no existe una teoría que describa la personalidad del delincuente sexual bajo estándares basados en características homogéneas por cuanto cada individuo se enfrenta a factores que en muchos casos son de naturaleza interviniente y a aquellos relativos a su propio interés sexual.

3. Con base en la categorización que se ha desarrollado sobre el delito sexual, tanto el derecho como la criminología, se puede afirmar que ambas ciencias han llegado a consideraciones coincidentes en las tipologías de este tipo de conducta ilícita, sin embargo, desde la arista de la norma positiva, resulta necesario establecer la armonía en cuanto a las políticas a implementar, dependiendo del tipo de delito sexual y siguiendo las motivaciones del derecho penitenciario.

4. En relación con las consecuencias del delito sexual, desde la visión jurídica, se ubican primordialmente en la víctima por constituirse en el bien jurídico protegido y desde el enfoque criminológico la principal consecuencia de la delincuencia sexual se sintetiza en el cambio de la vida de la víctima relacionada a sus costumbres, a su entorno familiar y en fin al entorno social.

5. En materia de delitos sexuales, la principal contribución de la criminología a la sociedad debe orientarse al desarrollo de modelos de prevención y, por lo tanto, fundamentados en lineamientos estratégicos concentrados, por una parte, en los factores determinantes de este tipo de delitos, y por la otra, en el diseño de políticas criminales dirigidas no solo a atenuar las consecuencias en las víctimas, también encaminadas al aseguramiento de escenarios familiares y sociales que eviten la formación de delincuentes sexuales potenciales. 


\section{Referencias}

Ávila, K. (2005). "Aproximación a las propuestas de prevención y control del delito desde la criminología crítica." Revista Capitulo Criminológico, 37 (3), pp. 39-117.

Código Penal (2005). Gaceta Oficial de la República de Venezuela, 5768, abril 13, 2005.

Correa, J. (2006). Fundamentos de la criminología. [Documento en línea]. Disponible en: http://correalex.blogdiario.com/ 1141496460/.

Chirinos, Y. (s/f). Delitos sexuales. Aspectos médicos y forenses y criminalísticos. [Documento en línea]. Disponible en: http://www.ceav.com.ve/apureceav /DRISMAELCHIRINOSDELITOS SEXUALES.ppt.

De la Puente, P. y Torres, E. (2000). "Seguridad y prevención del delito. Un análisis crítico de los modelos y estrategias contra la criminalidad". Revista de Estudios Criminológicos y Penitenciarios. 1, pp. 21-73.

Devoto, E. y Aravena L. (2003). Pedofilia: un punto de vista criminológico. [Revista en línea]. Disponible en: http://www.scielo.cl /scielo.php?pid = S003498872003001200017\& script=sci_arttext.

Echebúrúa, E. y de Corral, P. (2006). "Secuelas emocionales en víctimas de abuso sexual en la infancia." Revista Cuadernos de Medicina Forense [en línea], pp. 43-44. Disponible en: http://scielo.isciii.es/scielo.php.

Eysenck, H.J. (1952). "The effects of psychotherapy: An evaluation". Fournal of Consulting Psychology, 16, pp. 319-324.

Eysenck, H. J. y Eysenck, S. B. G. (1976). Psychoticism as a dimension of personality. London: Hodder and Stoughton.

Eysenck, H. J. (1985). Personality and individual differences: A natural science approach. New York: Plenum.

Eysenck, H. J. (1994). "Creativity and personality: Word association, origence, and psychoticism." Creativity Research Fournal, 7, p.p. 209-216.

Fuenmayor, F. (2009). "Consideraciones sobre los cambios introducidos con la ley de reforma parcial del Código Penal en materia de delitos sexuales." Revista Capitulo Criminológico, 37 (3), pp. 39-117.

Garrido, V. (1989). "Psicología de la violación." Revista de Estudios de Psicología, 38, pp. 91-110. 
Gómez, V. (1995). El pequeño Larousse. Buenos Aires: Ediciones Larousse.

González, P. (s/f). Perfiles criminológicos de delincuentes sexuales y homicidas. [Documento en línea]. Disponible en: http://www.alfonsozambrano.com/doctrina_penal/280709/ dp-perfiles_criminologicos_homicidas.doc.

Groth, A.N. (1979). Men who rape: The psychology of the offender. New York: Plenum Press.

Hikal, W. (2010). El estudio de la personalidad antisocial desde la perspectiva psicoanalítica y conductual (sistematizando el conocimiento criminológico y psicológico). [Documento en línea]. Disponible en: http://www.polizei-newsletter.de/documents/WaelHikal.pdf.

Ley Orgánica para la Protección de Niños, Niñas y Adolescentes (2007). Gaceta Oficial de la República de Venezuela, Extraordinario, 5859, diciembre 10, 2007.

Lomelí, M. y García, B. (2000). "Delincuentes sexuales que llegan a un CERESO y su tipificación." Revista Facultad de Medicina de la Universidad Nacional Autónoma de México, 43 (6), pp. 20-225. [Documento en línea]. Disponible en: http://www.ejournal.unam.mx/ rfm /no43-6/RFM43603.pdf.

López, B. (1971). Violación, estupro, abuso deshonesto. Buenos Aires: Ediciones Lerner.

Marchiori, H. (s/f). Víctimas vulnerables: niños víctimas de abuso sexual. [Documento en línea]. Disponible en: http://www.ilanud.or.cr/A119.pdf.

Martínez, J. (2001). Abuso sexual contra el niño y el adolescente en el derecho penal sustantivo venezolano. Anuario de Derecho, 23, pp. 278-296.

Martínez, P. y Otros (2008). Factores de riesgo predisponentes a la delincuencia en una población penal femenina. Revista Enseñanza e Investigación en Psicología, 13(2), 301318. [Documento en línea]. Disponible en: http://redalyc.uaemex.mx/pdf/292 /29213207.pdf.

Posada, E. y Salazar J. (2005). Aproximaciones criminológicas y de la personalidad del abusador sexual. Trabajo de Grado como requisito para optar al grado de Abogado no publicado. Universidad Católica de Oriente, Río Negro, Antioquia, Colombia.

Romi, J. (2010). Los delitos sexuales: Encuadre jurídico y algunas reflexiones médico legales. [Documento en línea]. Disponible en: http://www.aap.org.ar/publicaciones/forense/forense-9/tema-5.htm.

Schmidt y Otros (s/f). "Modelo psicobiológico de la personalidad de Eysenck: Una historia proyectada hacia el futuro." Revista Internacional de Psicología, 11 (2), pp. 1-21. [Documento en línea]. Disponible en: http://psicologiarevista.99k.org/Modelo\%20

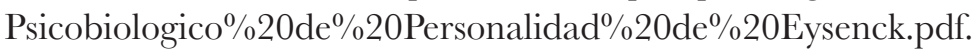


